УДК 069.5:069(470+571)

DOI: 10.32340/2414-9101-2021-2-24-29

И. А. Глуховских

Алтайский государственный институт культуры (Барнаул, Россия) iriscka@yandex.ru

Научный руководитель - И. В. Куприянова, доктор исторических наук, доцент Алтайский государственный институт культуры (Барнаул, Россия)

\title{
ОТКРЫТЫЕ ФОНДЫ КАК СПОСОБ АКТУАЛИЗАЦИИ МУЗЕЙНЫХ СОБРАНИЙ
}

Аннотация. На примере опыта работы крупнейших музейных учреждений современной России охарактеризованы особенности открытого хранения музейных фондов. Автор осмысливает актуальную тенденцию развития отечественного музейного дела, заключающуюся в пересмотре традиционного запрета на открытое экспонирование части особо ценных музейных предметов и коллекций, находящихся в фондохранилищах. Отмечается, что при обеспечении надлежащих условий хранения, оснащении фондохранилища специализированными инженерно-техническими средствами и системами долговременная сохранность экспонируемых ценных и особо ценных музейных предметов не ставится под угрозу.

Ключевые слова: музей, музейный фонд, музейные коллекиии, фондохранилище, открытое хранение фондов.

Музей, являясь некоммерческим учреждением культуры, создается для хранения, изучения и публичного представления культурных ценностей, совокупность которых составляет музейные фонды. Как правило, постоянные и временные экспозиции не позволяют представить собрание в полном объеме. Основная часть коллекций находится в специально оборудованных хранилищах со строго ограниченным доступом. В последние годы музеи преодолевают эту проблему через организацию открытого хранения фондов. Оно подразумевает использование специального оборудования (остекленных шкафов, витрин, откатных рам, выдвижных кассет, открытых стеллажей), при размещении в которых часть музейных предметов может быть доступна для обзора. Таким образом, появляется возможность осуществлять показ музейных предметов более широкому кругу посетителей.

Исследователи отмечают, что тенденция открытого хранения зародилась в 1970-х годах в Музее антропологии Университета Британской Колумбии как попытка «демократизировать» музейные выставки. В 1982 году была поддержана музеем Стронг (Strong Museum, Рочестер, НьюЙорк). Первое отрытое хранение (visible storage) появилось в 1988 году в музее Метрополитен (Нью-Йорк). В Американском крыле был организован Исследовательский центр Генри Р. Люса по изучению американского искусства (Henry R. Luce Center for the Study of American Art), где выставили 18312 предметов (около 80 \% коллекции американского изобразительного и декоративноприкладного искусства) [1]. Следует отметить, что практика открытого показа фондов получила на Западе широкое распространение.

В России одним из первых открыл свои фонды Государственный Эрмитаж. В 2003 году на севере Петербурга были открыты первые корпуса реставрационно-хранительского центра «Старая деревня», известного также как Фондохранилище Государственного Эрмитажа. Генеральный план строительства, утвержденный в 1984 году, не подразумевал открытый показ фондов для публики, но в процессе реализации концепция поменялась. Первый камень был заложен в 1990 году. В 2012 году завершилась вторая очередь строительства, сейчас ведутся работы по строительству третьей очереди. 
В настоящее время реставрационно-хранительский центр «Старая деревня» представляет комплекс зданий, включающий фондохранилище, выставочно-лекционный, реставрационный, инженерный и административный корпуса. Здесь расположены реставрационные лаборатории, лаборатория биологического контроля, выставочные залы. С 2006 года работает археологический класс по программе по программе «Прошлое на кончиках пальцев» для слабовидящих и незрячих детей.

В основном Фондовом корпусе, оснащенном специально спроектированным музейным оборудованием, современными электронными системами безопасности и климатического контроля, разместились коллекции отдела западноевропейского прикладного искусства, отдела западноевропейского изобразительного искусства, отдела истории русской культуры, отдела Востока, отдела археологии Восточной Европы и Сибири и отдела Античного мира. Каждое из хранилищ формировалось по отдельному проекту. Комплекс создавался с применением принципа открытого хранения, что отличает его от традиционных музейных хранилищ. Тысячи экспонатов доступны для осмотра посетителями. Познакомиться с коллекциями можно только в составе экскурсионной группы, которая передвигается по фиксированному маршруту [2].

Еще одним музеем, претендующим на первенство во внедрении открытой формы хранения, стал Государственный Русский музей. В 2005 году в Михайловском (Инженерном) замке был открыт фонд скульптуры, насчитывающий 134 работы конца XIX - начала XX века. По словам сотрудников, он стал преемником подобного хранилища, созданного к 100-летию музея в 1998 году во флигеле Росси. В новом проекте для демонстрации были использованы специальные витрины с информационной компьютерной программой, содержащей необходимые сведения о скульптоpax, об исторических лицах, запечатленных в портретах. Фонд можно посмотреть в режиме работы музея.

Через два года на третьем этаже Михайловского замка открыли доступ к фонду скульптуры XX века. В витринах и на постаментах были размещены около 200 лучших произведений отечественной пластики (от авангарда 1920-х годов до экспериментальных работ современных художников), не вошедшие в постоянную экспозицию музея. Доступ организованным группам посетителей осуществлялся два дня в неделю по предварительной записи. [3].

Несколько десятилетий существует открытое хранение в Государственном центральном музее современной истории России (Москва). В запасниках представлены первые экземпляры советского агитационного фарфора, образцы иностранной керамики, резная кость, лаковые миниатюры, декоративные стеклянные и фарфоровые вазы. Эти и многие другие предметы в свое время были подарками советским вождям от соотечественников и руководителей иностранных государств. Экскурсии проводят хранители коллекций по предварительной записи. Кроме того, в настоящее время есть возможность совершить виртуальный тур по открытому хранению [4].

В 2012 году в Государственном музее истории Санкт-Петербурга было создано открытое хранение фонда декоративно-прикладного искусства. В специально оборудованных помещениях Никольской куртины (левая сторона) Петропавловской крепости разместили более 500 предметов мебели XVIII-XX вв. Начало этой работе в музее истории Санкт-Петербурга было положено еще в 1990-е годы. Хранитель фонда декоративно-прикладного искусства проводила экскурсии по хранилищу, расположенному в Нарышкинском бастионе Петропавловской крепости, прекратившиеся с уходом сотрудника на пенсию [5].

В 2013 году год в правой стороне Петровской куртины были открыты фонды керамики и стекла. Из всей коллекции, насчитывающей более двенадцати тысяч предметов, в открытом хранении представлено около пяти тысяч изделий ведущих стекольных и фарфоровых заводов России и Европы [6]. Посещение осуществляется организованными группами два раза в неделю по предварительным заявкам.

В 2014 году для посетителей открылось фондохранилище Государственного историко-архитектурного и этнографического музея-заповедника «Кижи». В 2006 году музею было передано здание мастерских ремесленного училища в Петрозаводске, построенное в 1914 году. В 2012 году после завершения реконструкции и введения в эксплуатацию систем фондохранения в новые 
помещения, оснащенные специализированным оборудованием, были перемещены реставрационные мастерские, научно-фондовая документация, рабочие места сотрудников, перевезено 34546 предметов [7, с. 22].

В хранилищах сотрудники поместили коллекции дерева, текстиля, металла и меднолитой пластики, археологии, древнерусской и современной живописи и т. д. При этом посетители имеют доступ лишь к части коллекций, выставленных в закрытых витринах. Экскурсии проводятся по предварительным заявкам. Помещения, в которых располагаются коллекции «Фотоматериалы», «Письменные источники» и «Чертежи», закрыты для посещений из-за особенностей условий хранения. Доступ к ним обеспечивается в виде электронных презентаций в методическом кабинете [8].

В соответствии с Концепцией развития музея-заповедника «Кижи» на 2017-2027 годы запланировано строительство на острове Кижи специализированного экспозиционного реставрационно-хранительского комплекса, также открытого для посещения специализированными группами. Это позволило бы не только создать оптимальные условия хранения, освободить памятники народного зодчества, ранее занятые под депозитарии фондовых коллекций, но и расширить доступ посетителей к музейным ценностям [9].

Особого внимания заслуживает опыт Политехнического музея (Москва). В 2013 году было закрыто на реконструкцию историческое здание. Для временного размещения музейного фонда и библиотеки, а также для развития реставрационной деятельности, были арендованы и оборудованы в соответствии с современными музейными стандартами площади на территории Технополиса «Москва» (на территории бывшего завода АЗЛК). С декабря 2014 года эта площадка работает в режиме открытого хранения.

Определенные трудности при реализации проекта для сотрудников музея представляло помещение, неприспособленное для приёма посетителей, невозможность отделить в хранилище публичную зону от рабочей и многие другие проблемы. В настоящее время фондохранилище организовано сочетанием островов крупногабаритного хранения и многоэтажными стеллажами. Среди экспонатов расположены лайтбоксы с описаниями основных этапов реконцептуализации музея. Открытые фонды демонстрируют разнообразие и богатство коллекций Политехнического музея. Посещение организовано в виде экскурсий, во время которых можно узнать об истории формирования коллекций, работе музейных специалистов по атрибуции, изучению предметов, научной реставрации и др. [10].

С 2015 года постепенно открывает фонды Государственный музей истории религии (СанктПетербург). Первой стала масонская коллекция, насчитывающая несколько тысяч предметов. Она охватывает историю движения в разных странах с конца XVIII века и до 1930 -х гг. Сотрудники музея подготовили часть хранилища для посещения, пытаясь сочетать обеспечение безопасности и удобство осмотра. В 2016 году открыли для регулярного посещения японскую коллекцию, которая насчитывает около 700 экспонатов, в том числе нэцкэ, мелкую и крупную пластику, ритуальные предметы, принадлежности для письма, графику и т. д. В декабре 2017 года посетителям были представлены фонды, где хранится коллекция западноевропейской живописи. Собрание включает около 200 произведений религиозного и светского искусства XIV-XX вв. В начале 2019 года открыли фонд религиозной и светской русской масляной живописи. Коллекция насчитывает более 250 портретов, пейзажей, жанровых исторических и религиозных произведений XVIII-XXI веков. Рассказ хранителей или экскурсоводов включает информацию о коллекциях, принципах организации хранения, работе ответственных хранителей и т. д. [11].

Среди сибирских музеев одним из первых, открывшим фонды для посетителей, стал Томский областной художественный музей. В 2004 году были созданы «Открытые фонды скульптуры», демонстрирующие произведения из запасников [12]. Данный проект сочетает экспозицию (показ отдельной стоящих скульптур) и фрагмент фондохранилища (работы на стеллажах за прозрачным барьером) [13]. 
В 2010 году доступ в фондохранилище для организованных групп открыл Красноярский краевой краеведческий музей. Система открытого хранения была введена в 2001 году, но почти 10 лет фонды могли посещать только почетные гости, преподаватели и студенты [14].

Опыт открытого хранения фондовых материалов имеет Тобольский историко-архитектурный музей-заповедник, входящий в состав Тюменского музейно-просветительского объединения. С 2014 года он реализует проект - открытое фондохранилище «Временно доступен». В шести помещениях Рентереи - уникального сооружения ансамбля Тобольского Кремля, построенного в XVIII веке по проекту С. У. Ремезова - разместились коллекции «Археология», «Палеонтология», «Дерево», «Русская этнография», «Приборы и техника», «Природа». Во время экскурсий происходит знакомство с наиболее яркими экспонатами, осуществляется показ системы хранения коллекций [15].

Открыли свои фонды и другие структурные подразделения Тюменского музейно-просветительского объединения. В Музейном комплексе им. И. Я. Словцова (г. Тюмень) проект реализуется с мая 2017 года в виде отдельных экскурсий, знакомящих посетителей с коллекциями «Оружие», «Вооружение», «Нумизматика», «Археология» и др. В 2018 году Ялуторовский музейный комплекс представил открытое хранение, где размещены медная посуда и кухонная утварь конца XIX - начала XX веков, различная бытовая техника 1940-1970-х годов, орудия труда, предметы этнографии, керамика, стекло, часть коллекций дерева и тканей [16].

Музей геологии, нефти и газа (г. Ханты-Мансийск) представил в экспозициях открытого фондохранения часть коллекции минералов (около 200 единиц), коллекцию предметов декоративноприкладного искусства, выполненных из горных пород, минералов, современную художественную керамику. Помещения фондохранилища оснащены уникальным технологическим оборудованием, позволяющим музейным предметам находиться в условиях открытого доступа для посетителей [17].

Отдельную группу составляют музеи военно-исторического профиля, для которых является распространенной практикой экспонирование вооружения на открытом воздухе. Некоторые целенаправленно демонстрируют военную технику на открытых площадках для привлечения внимания. Однако многим музеям приходится прибегать к этому по необходимости, так как конструкции помещений не позволяет размещать в них экспонаты.

В Военно-историческом музее артиллерии, инженерных войск и войск связи (Санкт-Петербург) в 2002 году была открыта для посетителей обновленная территория открытого хранения, представившая экспозицию «История создания материальной части артиллерии, ракетного вооружения, инженерной техники и техники войск связи». Пятнадцать тематико-экспозиционных комплексов демонстрируют развитие отечественной и зарубежной оружейной мысли, историю отдельных типов вооружения. Обширная территория внутреннего двора Кронверка позволила разместить на специальных основаниях и подставках более 300 экспонатов [18].

Еще одной категорией музеев, чьи фондовые коллекции хранятся открыто, стали этнографические музеи под открытым небом. Обычно в них сохраняются недвижимые объекты наследия: жилые, общественные, хозяйственные постройки, в ряде музеев сохраняется историко-культурная среда. Экспозиция формируется на открытом пространстве за счет комбинации построек, сохраненных на месте, свезенных и новодельных объектов. В музеях такого типа перемещенные архитектурные памятники и новоделы могут учитываться как музейный предмет в составе основного или научно-вспомогательного фондов [19]. Это создает проблемы, связанные с дальнейшим использованием памятников, невозможностью обеспечить надлежащие условия хранения.

Тенденции создания открытого фондохранилища заложены архитекторами при проектировании нового здания Государственного художественного музея Алтайского края (г. Барнаул). Для реализации этого замысла была выбрана античная коллекция музея, насчитывающая 30 произведений подлинной античной керамики и 15 слепков с античной скульптуры, которые поступили из отдела античного мира Государственного Эрмитажа.

Для размещения коллекции запланировано выделить небольшое помещение на закрытой территории фондохранилища. Крупная скульптура разместится на подиумах в центре зала. 
Барельефы будут помещены в пылезащитные пристенные витрины. Для терракоты, античной керамики, скульптурных портретов предполагается изготовить специализированное оборудование, позволяющее индивидуально осматривать каждый экспонат со всех сторон.

Все вышеизложенное свидетельствует о том, что в последние годы проекты, связанные с открытым хранением фондов, реализуются все чаще. Это существенно расширяет доступ посетителей к коллекциям, позволяет показать ранее не экспонировавшиеся музейные предметы. Однако, несмотря на применение специализированного оборудования, режим хранения некоторых коллекций не позволяет постоянно их демонстрировать. Допуск в открытые фонды музеев, чья деятельность не связана с необходимостью хранить и экспонировать предметы вне помещений, организуется в виде экскурсий для небольших групп. В одних музеях разработаны и опубликованы графики посещений, в других визит возможен по предварительной заявке.

Стремление к открытому показу фондов нашло отражение в Стратегии развития деятельности музеев в Российской Федерации на период до 2030 года, одобренной Общим собранием Союза музеев России 14 ноября 2018 года. Одной из задач стала разработка программы реконструкции и модернизации фондохранилищ музеев с созданием, при возможности и целесообразности, зон «открытого хранения» [20].

\section{Список литературы}

1. Bohlen, C. Museums as Walk-In Closets; Visible Storage Opens Troves to the Public // The New York Times. - 2001. - May 8. - URL: https://www.nytimes.com/2001/05/08/arts/ museums-as-walk-in-closets-visible-storage-opens-troves-to-the-public.html?pagewanted=all\&src=pm (дата обращения: 12.02.2021).

2. Реставрационно-хранительский центр Государственного Эрмитажа «Старая Деревня» (г. Санкт-Петербург). - Москва : Проектное бюро Спутник, 2012. - 32 с. : цв. ил. - (Музейный гид, 2012. Коллекции). - $\quad$ URL: https://www.fondpotanin.ru/upload/ iblock/e9b/e9b020a8b268998e1146fc7507aaa059.pdf (дата обращения: 12.02.2021).

3. Михайловский (Инженерный) замок // Музеи России : [сайт]. - Москва, 1996-2021. URL: http://museum.ru/M158 (дата обращения: 12.02.2021).

4. Открытое хранение коллекций декоративно-прикладного искусства // Theory \& Practice $=$ Теории и практики : [сайт]. - [...], 2009-2021. - URL: https://theoryandpractice.ru/ seminars/43865-otkrytoe-khranenie-kollektsiy-dekorativno-prikladnogo-iskusstva (дата обращения: 12.02.2021).

5. Минкина, Е. В. Особенности экскурсионного обслуживания посетителей в Открытом хранении коллекции мебели // Труды Санкт-Петербургского государственного университета культуры и искусств. - 2015. - Т. 212. - С. 271-275.

6. Коллекция фарфора и стекла XVIII-XXI веков // Государственный музей истории СанктПетербурга: [сайт]. - Санкт-Петербург, [...]. - URL: https://www.spbmuseum.ru/ exhibits_and_exhibitions/92/4968/ (дата обращения: 12.02.2021).

7. Отчёт о деятельности Государственного историко-архитектурного и этнографического музея-заповедника «Кижи» в 2012 г. / [под общ. ред. А. В. Нелидова ; сост., отв. ред. Н. М. Мельникова]. - Петрозаводск : Изд. центр музея-заповедника «Кижи», 2013. - 64 с. : ил.

8. Первая экскурсия в фондохранилище музея «Кижи» // Государственный историко-архитектурный и этнографический музей-заповедник «Кижи» : [сайт]. - Кижи, 2005-2021. - URL: http://kizhi.karelia.ru/info/en/about/pressrelease/2014/9274.html (дата обращения: 12.02.2021).

9. Концепция развития музея-заповедника «Кижи» на 2017-2027 гг. // Государственный историко-архитектурный и этнографический музей-заповедник «Кижи» : [сайт]. - Кижи, 2005-2021. - URL: http://kizhi.karelia.ru/media/info/files/attached/1703/kontseptsiya_razvitiya_muzeya_na_ 09.06.2016_.pdf (дата обращения: 12.02.2021).

10. Галактионов, С. Практики открытого хранения музейных фондов // Политехнический музей. - Москва, 2005-2021. - URL: https://polytech.bm.digital/exhibition/ 816910995174219835/praktiki-otkryitogo-hraneniya-muzejnyih-fondov (дата обращения: 12.02.2021). 
11. Экскурсии по Фондам открытого хранения // Государственный музей истории религии : [сайт]. - Санкт-Петербург, 2020. - URL: https://gmir.ru/info/programm/fondy_open/ (дата обращения: 12.02.2021).

12. История [Томского областного художественного музея ] // Томский областной художественный музей : [сайт]. - Томск, 2008-2021. - URL: http://artmuseumtomsk.ru/page/19 (дата обращения 12.02.2021).

13. Скульптура [в собраниях Томского областного художественного музея ] // Томский областной художественный музей : [сайт]. - Томск, 2008-2021. - URL: http://artmuseumtomsk.ru/page/122 (дата обращения: 12.02.2021).

14. Открытое хранение // Красноярский краевой краеведческий музей : [сайт]. - Красноярск, [...]. - URL: http://www.kkkm.ru/o-muzee/kollekcii/otkrytoe-hranenie (дата обращения: 12.02.2021).

15. Загваздина, Я. Г. Рентерея в Тобольске: история и современность // Баландинские чтения : сб. ст. науч. чтений памяти С. Н. Баландина (Новосибирск, 15-17 апр. 2015 г.). - Новосибирск : Новосибирская гос. арх.-худ. академия, 2015. - Т. Х, ч. 1. - С. 61-68.

16. 2017. Год музейной революции : инф.-аналит. отчёт о работе ГАУК ТО «Тюменское музейно-просветительское объединение» за 2017 год / под общ. ред. С. Ю. Сидоровой. - Тюмень : ГАУК ТО «Тюменское музейно-просветительское объединение», 2018. - 64 с.

17. Открытое фондохранение // Музей геологии, нефти и газа : [сайт]. - Ханты-Мансийск, 2010-2021. -URL: http://muzgeo.ru/otkrytoe-fondokhranenie.php (дата обращения: 12.02.2021).

18. Веселов, Ф. Н. Экспозиция открытого хранения вооружения и военной техники Военно-исторического музея артиллерии, инженерных войск и войск связи: история и предшественники / Ф. Н. Веселов, Т. И. Карлина // Вопросы музеологии. - 2017. - № 2. - С. 97-110.

19. Кимеева, Т. И. Проблемы фондовой деятельности в этнографических музеях под открытым небом Западной Сибири / Т. И. Кимеева, С. А. Пронина // Вестник Кемеровского государственного университета культуры и искусств. - 2015. - № 30. - С. 122-129.

20. Стратегия развития деятельности музеев в Российской Федерации на период до 2030 года // Союз музеев России : [сайт]. - Москва, [...]. - URL: http://www.souzmuseum.ru/ index.php?option=com_content\&view=article\&id=22197:strategiya-razvitiya-deyatelnosti-muzeev-vrossijskoj-federatsii-na-period-do-2030-goda\&catid=10589\&Itemid=176 (дата обращения: 12.02.2021).

Irina A. Glukhovskih

Altai State Institute of Culture (Barnaul, Russia) iriscka@yandex.ru

Scientific Chief - Irina V. Kuriianova, Dr. Of Historical Sciences, Associate Professor Altai State Institute of Culture (Barnaul, Russia)

\title{
OPEN STOCK AS A WAY OF POPULARIZATION OF MUSEUM COLLECTIONS
}

\begin{abstract}
Drawing on the example of the work of biggest museum institutions of the today's Russia, the author of the article describes peculiarities of open keeping of museum stock, interprets actual trend of development of Russian museum sector that lies in reverse a prohibition on open showing of most valuable part of museum items and collections. It is noticed that while maintaining keeping conditions and instrumentation of museum depository with engineering and technical means and systems, long-term safety of the most valuable museum items is beyond danger.

Keywords: a museum, museum stock, museum collections, museum depository, open keeping of museum stock.
\end{abstract}

